\title{
DO DEVER DE FUNDAMENTAR AS DECISÕES JUDICIAIS SOB O PRISMA CONSTITUCIONAL E O NOVO CÓDIGO DE PROCESSO CIVIL
}

\author{
Luana Amaral Assunção Correa, Nayara Maria Silverio da Costa Dallefi Oliveira
}

Universidade do Oeste Paulista, curso de Direito, Presidente Prudente, SP. E-mail: luana amaraal@hotmail.com

\section{RESUMO}

O dever de fundamentar as decisões judiciais está previsto no art. 93, inciso IX, da Constituição Federal de 1988, de modo que o julgador deverá demonstrar as razões que o levaram a prolatar determinada decisão. Assim, o presente estudo tem o intuito de abordar a necessidade de fundamentação das decisões judiciais, exigência já então consagrada na Carta Magna, que com o novo código de processo civil, reafirmar ainda mais tal prerrogativa em nome da segurança jurídica. A partir de pesquisas bibliográficas, pode-se concluir que a necessidade de fundamentação das decisões judicias, com previsão também na legislação infraconstitucional, vislumbra-se como um dos mecanismos para garantia da segurança jurídica, de modo que busca conferir mais previsibilidade e racionalidade.

Palavras-chave: Dever de fundamentar, Carta Magna, Novo Código de Processo Civil, Segurança jurídica.

\section{OF THE DUTY OF FUNDING THE JUDICIAL DECISIONS UNDER THE CONSTITUTIONAL PRISM AND THE NEW CIVIL PROCESS CODE}

\begin{abstract}
The duty to justify judicial decisions is provided in art. 93, item IX, of the Federal Constitution of 1988, so that the judge must demonstrate the reasons that led him to proclaim a decision. Thus, the present study intends to address the need for justification of judicial decisions, a requirement already enshrined in the Charter, which with the new civil procedural code, reaffirm this prerogative in the name of legal certainty. Based on bibliographical research, one can be concluded that the need for justification of judicial decisions, also foreseen in infraconstitutional legislation, is seen as one of the mechanisms to guarantee legal certainty, so that it seeks to confer more predictability and rationality.

Keywords: Duty to substantiate, Magna Carta, New Code of Civil Procedure, Legal security.
\end{abstract}

\section{INTRODUÇÃO}

O dever de fundamentar as decisões judiciais está previsto no art. 93, inciso IX, da Constituição Federal de 1988, de modo que julgador deverá demonstrar as razões que o levaram a prolatar determinada decisão.

Nesse diapasão, em consonância com a Carta Magna de 1988, a fundamentação das decisões judiciais, ao que consta foi uma das preocupações do legislador, quanto à nova legislação infraconstitucional processual civil, tendo em vista o intuito de reforçar em diversos dispositivos do diploma legal, a necessidade de fundamentação.

Nesta toada, o presente estudo tem o intuito de abordar a necessidade da fundamentação das decisões judiciais, exigência já então consagrada na Norma Superior, que com a nova legislação infraconstitucional, veio para respaldar ainda mais tal prerrogativa em nome da segurança jurídica.

\section{METODOLOGIA}

A pesquisa bibliográfica foi o principal meio de obtenção de informações neste trabalho ao lado da legislação. No presente estudo, partindo-se do raciocínio hipotético dedutivo, foram construídas as bases do trabalho, numa interpretação reflexiva e dialética.

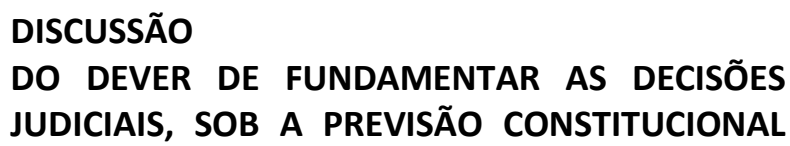




\section{DO ART. 93, INCISO IX, DA CONSTITUIÇÃO FEDERAL DE 1988}

A promulgação da Constituição Federal de 1988, representa a transição de um Estado autoritário para um Estado Democrático de Direito, instituído logo no preâmbulo, da então vigente Carta Magna (BARROSO,2015).

Segundo Barroso (2015, p. 493):

A Constituição de 1988 foi rito de passagem para a maturidade institucional brasileira. Nos últimos vinte anos, superamos todos os ciclos do atraso: eleições periódicas, Presidentes cumprindo seus mandatos ou sendo substituídos na forma constitucionalmente

prevista, Congresso Nacional em funcionamento sem interrupções, Judiciário atuante e Forças Armadas fora da política.

Sob este novo contexto, diferente da Carta de 1967 e da Emenda Constitucional n. $1 / 69$, consagrou-se expressamente no novo texto constitucional, em disposições gerais pertinente ao Poder Judiciário, nos termos do art. 93, inciso $\mathrm{IX}^{1}$, que todos os julgamentos dos órgãos do Poder Judiciário serão públicos, e fundamentadas todas as decisões, sob pena de nulidade (TAVARES, 2012).

Nesta toada, ao assegurar que todas as decisões serão fundamentadas, impõe ao julgador, demonstrar as razões que o levaram a proferir determinada decisão, em contrapartida permite que as partes e a sociedade tomem conhecimento dos motivos que levaram aquela decisão (MENDES; STRECK, 2013).

Para Mendes e Streck (2013, p. 1324):

A fundamentação das decisões - o que, repitase, inclui a motivação mais do que uma

\footnotetext{
${ }^{1}$ Art. 93, caput: Lei complementar, de iniciativa do Supremo Tribunal Federal, disporá sobre Estatuto da Magistratura, observados os seguintes princípios:

$[\ldots]$

IX - Todos os julgamentos dos órgão do Poder Judiciário serão públicos, e fundamentadas todas as decisões, sob pena de nulidade, podendo a lei limitar a presença, em determinado atos, às próprias partes e a seus advogados, ou somente a estes, em casos nos quais a preservação do direito à intimidade do interessado no sigilo não prejudique o interesse público à informação (Redação dada pela Emenda Constitucional no 45, de 2004)
}

exigência própria do Estado Democrático de Direito, é um direito fundamental do cidadão. Fundamentação significa não apenas explicitar o fundamento

legal/constitucional da decisão. Todas as decisões devem estar justificadas e tal justificação deve ser feita a partir da invocação de razões e oferecimento de argumento de caráter jurídico. O limite mais importante das decisões judiciais reside precisamente na necessidade da motivação/justificação do que foi dito. Trata-se de uma verdadeira "blindagem" contra julgamentos arbitrários. 0 juiz ou o Tribunal, por exemplo, devem expor as razões que os conduziram a eleger uma solução determinada em sua tarefa de dirimir conflitos. Não é da subjetividade dos juízes ou dos integrantes dos Tribunais que deve advir o sentido a ser atribuído à lei, caindo por terra o antigo aforismo de que "sentença vem de sentire", erigido no superado paradigma da filosofia da consciência.

Logo, o dever de fundamentar as decisões judiciais, não deve ser visto apenas como simples requisito, mas como um direito fundamental do cidadão, frente a um Estado democrático de direito.

E ainda, que não houvesse previsão em âmbito constitucional, expressa nesse sentido, o dever de fundamentar não deixaria de corresponder a um direito fundamental do jurisdicionado, uma vez que é corolário da garantia do devido processo legal e manifestação do Estado de Direito. O dever de fundamentar compõe o conteúdo mínimo do devido processo legal (DIDIER JUNIOR, 2015).

Ademais, a exigência da fundamentação não interessa apenas as partes do processo, mas 
também a sociedade, uma vez que tal garantia apresenta dupla função.

Nesse sentido, Souza Neto (2015, p. 67) preceitua:

De um lado, a motivação das decisões judiciais fornece elementos para que as partes analisem as razões do juiz, podendo recorrer a uma instância superior. Por outro lado, a fundamentação das decisões judiciais interessa à própria sociedade, na medida em que a opinião pública e os próprios cidadãos são interessados nas manifestações judiciais. O processo não pode ser entendido como uma relação privada, restrita às partes e ao juiz. Ao contrário, diz respeito à toda a sociedade, na medida em que o próprio poder jurisdicional é uma delegação do poder do povo, conforme art. 1ㅇ da Constituição, e está sujeito ao controle difuso e democrático na complexidade das relações.

Portanto, o dever de fundamentar as decisões judiciais, consignado na Carta Magna de 1988, é de suma importância, que quando não observado implicará em nulidade.

\section{A FUNDAMENTAÇÃO DAS DECISÕES À LUZ DO CPC/2015}

O Código de Processo Civil de 2015, produzido e aprovado em um regime democrático, trouxe uma legislação infraconstitucional que observou as regras constitucionais implantadas com a Carta Magna de 1988.

Inclusive, preceituou-se no artigo $10^{2}$, do novo código que o processo civil será ordenado, disciplinado e interpretado conforme os valores e as normas fundamentais estabelecidos na Constituição da República Federativa do Brasil.

\footnotetext{
${ }^{2}$ Art. 10: O processo civil será ordenado, disciplinado e interpretado conforme os valores e as normas fundamentais estabelecidos na Constituição da República Federativa do Brasil, observando-se as disposições deste Código.
}

Logo, sob o prisma constitucional, quanto o dever de fundamentar as decisões judiciais, o novo código de processo civil reafirma em sua legislação a exigência da Norma Superior (93, IX), no art. $11^{3}$, caput, e no art. $489, \S 10^{4}$, acentua ainda mais tal prerrogativa.

Para Marinoni (2016, p. 169-170):

0 art. 11, CPC, apenas reproduz textualmente a Constituição, relegando para o seu art. 489 a tarefa de densificar infraconstitucionalmente o significado constitucional do dever de fundamentar.

$\mathrm{O}$ art. 489, §1으, diferente do código anterior (CPC, 1973), traz as hipóteses em que não se considera fundamentada qualquer decisão judicial, seja interlocutória, sentença ou acórdão.

Para Didier Junior (2015, p. 334):

$\mathrm{O}$ art. 489, §1으, do CPC traz inovação muito importante. Embora seu conteúdo já pudesse ser extraído do dever de fundamentar que decorre da Constituição Federal, é bastante salutar que agora algumas hipóteses em que se considera nãofundamentada a decisão judicial estejam previstas no texto legal. Isso permite um controle mais efetivo dos pronunciamentos judiciais, reduzindo a margem de subjetividade quanto à

\footnotetext{
${ }^{3}$ Art.11: Todos os julgamentos dos órgãos do Poder Judiciário serão públicos, e fundamentadas todas as decisões, sob pena de nulidade. ${ }^{4}$ Art. 489: São elementos essenciais da sentença:[...]

II - os fundamentos, em que o juiz analisará as questões de fato e de direito;[...]

$\S 1^{\circ}$ Não se considera fundamentada qualquer decisão judicial, seja ela interlocutória, sentença ou acórdão, que:

I - se limitar à indicação, à reprodução ou à paráfrase de ato normativo, sem explicar sua relação com a causa ou a questão decidida;

II - empregar conceitos jurídicos indeterminados, sem explicar o motivo concreto de sua incidência no caso;

III - invocar motivos que se prestariam a justificar qualquer outra decisão;

IV - não enfrentar todos os argumentos deduzidos no processo capazes de, em tese, infirmar a conclusão adotada pelo julgador; $V$ - se limitar a invocar precedente ou enunciado de súmula, sem identificar seus fundamentos determinantes nem demonstrar que o caso sob julgamento se ajusta àqueles fundamentos;

VI - deixar de seguir enunciado de súmula, jurisprudência ou precedente invocado pela parte, sem demonstrar a existência de distinção no caso em julgamento ou a superação do entendimento.
} 
percepção do que é e do que não é uma decisão fundamentada.

Logo, conforme salientado o art. 489, $\S 1$, apesar de ser considerado uma novidade do novo código de processo civil, o seu conteúdo é reflexo da previsão constitucional quanto o dever de fundamentar, buscando tal dispositivo respaldar ainda mais esse direito, em qualquer decisão judicial, seja interlocutória, sentença ou acórdão.

Por seu turno, Coêlho (2015, p.150-151) acrescenta:

\begin{abstract}
A norma exige do magistrado, entre outros aspectos, explicar a relação dos dispositivos legais mencionados na decisão com o caso concreto sob julgamento, contextualizar o emprego de conceitos jurídicos indeterminados, enfrentar todos os argumentos deduzidos no processo capazes de, em tese, infirmar a conclusão adotada pelo julgador e seguir os precedentes aplicáveis ao caso, fundamentando sua utilização. Esses requisitos proporcionam maior racionalização ao processo judicial, evitando decisões arbitrárias ou casuísticas, com pobreza argumentativa, por parte dos magistrados. 0 estabelecimento de parâmetros objetivos pelo referido dispositivo auxilia os advogados, as partes, o Ministério Público e os juízos revisores a fiscalizar a atuação judicial no que concerne ao cumprimento do dever de fundamentar a sentença.
\end{abstract}

Assim, a previsão de tais requisitos proporciona mais racionalidade ao processo, de maneira que afasta determinadas situações, que comprometem a fundamentação. Além do mais, permite um controle mais efetivo quanto 0 cumprimento do dever de fundamentar.
Portanto, o NCPC, não prioriza apenas o mérito das decisões judiciais, mas também por decisões judiciais que estejam devidamente fundamentadas.

\section{DO DEVER DE FUNDAMENTAR NO CPC EM NOME DA SEGURANÇA JURÍDICA}

O Novo Código de Processo Civil, em consonância com a Carta Magna de 1988, procurou implementar uma legislação infraconstitucional que atendesse aos atuais anseios do Poder Judiciário e da sociedade.

Sob tais circunstâncias, a fundamentação das decisões judiciais, ao que consta foi uma das preocupações do legislador, quanto a nova legislação infraconstitucional, tendo em vista que buscou-se reforçar em diversos dispositivos do diploma legal, a necessidade de fundamentação.

Para, Souza Neto $(2015$, p.71):

$\begin{array}{lcc}0 \quad \text { novo CPC } & \text { não } \\ \text { contemplou o } & \text { livre } \\ \text { convencimento do } & \text { juiz, }\end{array}$
que constava da legislação anterior. A democracia não é compatível com a tomada de decisões judiciais a partir de consciências pessoais. Nas duas únicas vezes que o novo código menciona o termo "convencimento", o legislador se preocupou em reforçar a necessidade de fundamentação das decisões. $O$ art. 371 estabelece que o juiz, ao apreciar a prova constante dos autos, deverá indicar na decisão "as razões da formação de seu convencimento". O art. 298 prescreve que mesmo quando $o$ juiz se manifestar sobre tutela provisória deverá motivar seu convencimento de modo "claro e preciso". Mais uma vez, verifica-se que todo o código é uma tentativa de conferir maior fundamentação, racionalidade e publicidade às decisões judiciais.

Outrossim, conforme já elucidado reafirma a previsão constitucional, quanto o 
dever de fundamentar as decisões judiciais e a publicidade dos julgamentos dos órgãos do Poder Judiciário, elementos estes importantes para garantia da segurança jurídica.

Nesse sentido, Ribeiro (2015, p.78):

[...] o novo código

estabelece no art. 110

dever de fundamentação

de todas as decisões do

Poder Judiciário, o que

apenas reforça a previsão

do art. 93, IX, da

Constituição Federal, que

ainda estabelece o dever

de publicidade das

decisões. Estes dois

elementos são

importantes para a

garantia de segurança

jurídica, conferindo maior

previsibilidade

uniformidade na formação

e no uso da jurisprudência.

Logo, ao reiterar na legislação infraconstitucional, o dever de fundamentar as decisões judicias, confere mais previsibilidade, tendo em vista que evita-se que as partes sejam surpreendidas com decisões de elevado grau de discricionariedade ou vagueza, uma vez que todas as decisões judiciais deverão ser devidamente fundamentadas (NETO, 2015).

Outrossim, o art. 489, $\$ 10$, ao trazer as hipóteses em que não se considera fundamentada uma decisão judicial, seja ela interlocutória, sentença ou acórdão, busca concretizar ainda mais a exigência constitucional, de maneira que traz mais racionalidade para o processo, assim como oferece melhor qualidade de julgados e auxilia as partes na verificação quanto ao cumprimento do dever de fundamentar.

Além do mais, quanto melhor fundamentada uma decisão, mais ela será capaz de servir como um bom precedente, na medida em que exigirá elevado grau de esforço argumentativo para sua superação, podendo inclusive servir de parâmetro para casos sucessivos que haja uma correlação (RIBEIRO, 2015).

Nesse diapasão, no tocante aos precedentes e o Novo Código de Processo Civil, Dallefi (2017, p.203), preceitua:

[...] se torna necessário, em nome da segurança jurídica, a utilização dos

$\begin{array}{lr}\text { mecanismos do } & \text { do } \\ \text { precedente com a } \\ \text { finalidade não só de } \\ \text { uniformizar a } \\ \text { jurisprudência, mas } \\ \text { também de proporcionar } \\ \text { um ordenamento mais } \\ \text { previsível isonômico e } \\ \text { razoável a todos os } \\ \text { jurisdicionados. }\end{array}$

Nessa toada, o dever de fundamentar em nome da segurança jurídica, demonstra-se através da importância dada pelo novo código, em reiterar a necessidade de fundamentar, a fim de trazer mais previsibilidade e racionalidade as decisões judiciais.

Portanto, a importância dada pelo novo código de processo civil quanto a fundamentação das decisões judicias, vislumbra-se como um dos mecanismos para a garantia da segurança jurídica.

\section{CONCLUSÃO}

Com o presente estudo, pode-se evidenciar que o novo código de processo civil, em consonância com a Carta Magna de 1988, procurou implementar uma legislação infraconstitucional que atendesse aos atuais anseios do Poder Judiciário e da sociedade.

Sob tais circunstâncias, a fundamentação das decisões judiciais, ao que consta foi uma das preocupações do legislador, quanto a nova legislação infraconstitucional, tendo em vista que buscou-se reforçar em diversos dispositivos do diploma legal, a necessidade de fundamentação, exigência já presente na Norma Superior.

Diante disso, a necessidade de fundamentação das decisões judicias, com previsão também na legislação infraconstitucional, vislumbra-se como um dos mecanismos para garantia da segurança jurídica, de modo que busca conferir mais previsibilidade e racionalidade.

\section{REFERÊNCIAS}

BARROSO, L.R. Curso de direito constitucional contemporâneo: os conceitos fundamentais e a construção do novo modelo. 5. ed. São Paulo: Saraiva, 2015.

COÊLHO, M.V.F. Garantias constitucionais e segurança jurídica. 1. ed. Belo Horizonte: Fórum, 2015. 
COÊLHO, M.V.F. et al. As conquistas da advocacia no novo CPC. Brasília: OAB, Conselho Federal, 2015.

DALLEFI, N.M.S.C. Da segurança jurídica da súmula vinculante no Brasil: Contribuições/Influências do Sistema da Common Law e Civil Law. São Paulo: Leme, 2017;

DIDIER JUNIOR, F.; BRAGA, P.S.; OLIVEIRA, R.A. Curso de direito processual civil. 11. ed. Salvador: Jus Podivm, 2016. v.2.

MARINONI, L.G. Comentários ao código de processo civil: artigos 1ำ ao 69. São Paulo: Revistas dos Tribunais, 2016, v.1.

MENDES, G. F.; STRECK, L.L. Comentário ao artigo 93. In: CANOTILHO, J.J. Gomes. Comentários à constituição do Brasil. São Paulo: Saraiva, Almedina, 2013.

RIBEIRO, C.S. O novo CPC e a garantia de segurança jurídica. In: COÊLHO, M.V.F. As conquistas da advocacia no novo CPC. Brasília: OAB, Conselho Federal, 2015.

SOUZA NETO, C.P. O novo CPC e a fundamentação das decisões judiciais. In: COÊLHO, M.V.F. As conquistas da advocacia no novo CPC. Brasília: OAB, Conselho Federal, 2015.

TAVARES, A.R. Manual do poder judiciário brasileiro. São Paulo: Saraiva, 2012;
Recebido para publicação em 05/06/2018 Revisado em 19/09/2018

Aceito em 21/09/2018 